ECONOMY

\title{
MATHEMATICAL-STATISTICAL ANALYSIS OF PRODUCTS SOLD IN ENTERPRISES
}

\author{
Taghiyeva T. A., Doctoral student of Azerbaijan State Oil and Industry University, Baku, Azerbaijan
}

DOI: https://doi.org/10.31435/rsglobal_conf/25032021/7468

Abstract. The demand for some oil mining equipment in the country is met by the activities of open
joint-stock companies with an oil mechanical engineering profile. Such enterprises include: Baku
Steel Ropes OJSC, Baku Oil Mining Equipment OJSC, Neftgazmash OJSC.
For the successful solution of many economic and social problems in the country, it is important to
increase labor productivity, the production of quality products, in short, improve the efficiency of all
social production.
In modern times, the increase in production efficiency in the country's economy is due to a number of
reasons. First, a very wide economic and scientific-technical potential has been created in the
country. A slight deviation from this potential means a large loss. Improving the use of individual
resources allows for greater economic gains. Second, the extensive factors of economic development
have exhausted themselves to some extent.

Keywords: efficiency, oil mechanical engineering, joint stock company, realized product, factors, mathematical-statistical model, regression, criteria, interpretation.

Introduction. In market relations, the rational use of past labor (fixed assets, raw materials, materials) in the conditions of high technical support of production is important.

With the development of scientific and technical progress, against the background of a general decrease in labor costs per unit of output, the share of materialized (past) labor is constantly increasing, and this is the essence of progress. In modern times, like other industries, the share of live labor in total production costs in oil engineering is up to $10 \%$. The use of fixed assets is important in increasing production efficiency, as well as increasing production. Rising economic growth increases the demand for raw materials. That is why the issue of rational use of material and energy resources to reduce the material capacity of the product is urgent.

Saving on material resources means saving on capital investment. Reducing the material capacity of the product is associated with improving its quality. Improving product quality provides great economic benefits by reducing the demand for resources, capital investment and operating costs.

Production of products in oil engineering enterprises is important for its realization and increase of economic efficiency. It is from this point that it is noted that economic growth in market relations is associated with the intensification of production, increasing the efficiency of rational use of labor, material and financial resources. There are many ways to increase production efficiency, the basics of which can be grouped as follows.

- Acceleration of scientific and technical progress and their application in oil engineering enterprises; production;

- Implementation of economic intensification with the application of the latest technology in

- Improving the management system, their methods and organizational structure;

- Application of new equipment and technology, digital technology in production;

- Improving the system and methodology of planning at the enterprise level, improving the system of technical and economic indicators and improving access to world experience for this purpose;

- Technical progress, the best direction of development, improvement of pricing policy aimed at improving product quality;

- Creation of conditions for the produced product to meet the world standards and introduction of the high quality product to the world market;

- Improving the interaction of other technical and economic indicators of the enterprise with the realized product;

- Realization of constant intensification of production process in oil engineering enterprises. 
Research methodology. Oil mechanical engineering enterprises have a special role in the economy of the Republic of Azerbaijan, where the study of production and sales is important. In addition to the methods known in statistics, such as grouping, comparison, systematization, dynamic series, probability theory, mathematical-statistical (correlation and regression modeling) methods were used to study the products sold in oil companies. The obtained models were tested by statistical criteria, its economic interpretation was carried out and analyzed by a number of statistical indicators.

Research results. The production program of each enterprise is of great importance in its production and economic activity. The volume, range and quality of the products produced are an integral part of the overall plan of the oil engineering enterprise. A very large amount of material resources and various equipment are used in the production process. That is why the maximum use of raw materials and production capacity in the planning work of oil refineries is reflected as an economic issue.

The production program has a comprehensive impact on the production and economic activities of the oil engineering enterprise. The production program determines costs, profits, profitability, labor productivity and other indicators, which imposes special requirements on the control of its design and implementation, and decisions are made to obtain its optimal version. The production program includes the following reports: volume and nomenclature of products produced in kind and value, volume and nomenclature of realized products, production capacity and use of fixed capital.

In market relations, each enterprise calculates these indicators for a long time in order to achieve strategic goals, and these reports are also made over the years. Current reports on production and sales are made on a monthly and quarterly basis. This is due to the fact that the consumption of individual products is not equal, there is a need to repair technological equipment, work is being done to increase production capacity, organizational and technical measures are being taken.

Quality and reliability of equipment in oil enterprises, assessment of the service life of this equipment in the oil industry, their maintenance, factors affecting production capacity, the relationship between oil and oil companies, the potential and value of the company, their analysis in the economic literature [1-5,7-10] has been extensively studied. However, it is important to study the products sold at oil companies and the factors that affect its level. This is also closely related to the issue of financial sustainability in these enterprises, and there is a need to use mathematical and statistical methods to address this issue. Based on the Aprior analysis, two indicators affecting the realized product (RM) were taken: the number of employees (IS) and labor productivity (LP), and a mathematical-statistical model was built between them.

Linear dependence was used to construct the regression model and is generally formulated as follows:

$$
\mathrm{y}=a_{0}+a_{1} x_{1}+a_{2} x_{2}+\cdots+a_{n} x_{n_{1}}, \quad i=\overline{1, n}
$$

Criteria and indicators known in mathematical statistics were used for the analysis of the obtained model [6].

Using the "Statistics" program, the input data of individual OJSCs were entered into the computer and the following regression model was obtained for BSR OJSC.

$$
R M_{1}=-331,8491+13,9546 \dot{\mathrm{I}} S_{1}+24,2246 \partial M_{1}
$$

Here $R M_{1}-$ Volume of products sold in BSR OJSC, thousand man

$\dot{\mathrm{I}} S_{1}$ - Number of employees in BSR OJSC, people

$\partial M_{1}$ - Labor productivity in BSR OJSC, man / person

The statistics of the obtained model are shown in the table below (Table 1).

It can be seen from Table 1 that the total correlation coefficient is $\mathrm{R}=0.9923$ and is very high. The critical (table) value of the F-Fisher coefficient characterizing the obtained model is 3.62 with a probability of $95 \%$, and its reported value is 64.7265 , i.e. the condition $F>F_{\text {krit }}$ is satisfied and the model is adequate. However, the P-significance indicator does not confirm the adequacy of the model, as the condition $F_{\mathrm{eh}}>0.05$ is not satisfied, ie $0.01521<0.05$. The analysis of $\mathrm{t}$-Student coefficients characterizing the individual coefficients of the regression model shows that the critical (table) value of this indicator is higher than some coefficients, ie $t>t_{\text {krit }}$ is not paid for these coefficients. Only in the labor productivity indicator $t>t_{k r i t}$, i.e. $t_{\partial h_{1}}>t_{k r i t}(4.9618>2.57)$ is satisfied. 
Table 1. Statistical indicators of the model

\begin{tabular}{|c|c|c|c|}
\hline Indicators & The sign & The Formula & Price \\
\hline 1 & 2 & 3 & 4 \\
\hline $\begin{array}{l}\text { total } \\
\text { correlation } \\
\text { coefficient }\end{array}$ & $R$ & $\sqrt{\frac{\sum_{i=1}^{n}\left(\tilde{y}_{i}-\bar{y}\right)^{2}}{\sum_{i=1}^{n}\left(y_{1}-\bar{y}\right)^{2}}}$ & 0,992363563 \\
\hline $\begin{array}{l}\text { determination } \\
\text { coefficient }\end{array}$ & $R^{2}$ & $\frac{\sum_{i=1}^{n}\left(\tilde{y}_{i}-\bar{y}\right)^{2}}{\sum_{i=1}^{n}\left(y_{1}-\bar{y}\right)^{2}}$ & 0,984785441 \\
\hline Standard error & $S_{i}$ & $\sqrt{\frac{\sum_{i=1}^{n} E_{i}^{2}}{n-2}}$ & 40,10640809 \\
\hline $\begin{array}{l}\text { sum of } \\
\text { squares } \\
\text { regression } \\
\text { residue } \\
\text { total }\end{array}$ & $\begin{array}{c}S S \\
S S_{\text {req }} \\
S S_{\text {resid }} \\
S S_{\text {req }}+S S_{\text {resid }}\end{array}$ & $\sum_{i=1}^{n}\left(\tilde{y}_{i}-\bar{y}\right)^{2}$ & $\begin{array}{l}208228,3178 \\
3217,0479 \\
211445,3657\end{array}$ \\
\hline $\begin{array}{l}\text { to a degree of } \\
\text { freedom } \\
\text { dispersion } \\
\text { regression } \\
\text { residue } \\
\end{array}$ & $\begin{array}{c}M S \\
S_{i}^{2} \\
S_{a o}^{2} \\
\end{array}$ & $\begin{array}{l}S S_{\text {req }} / K_{1} \\
S S_{\text {req }} / K_{2} \\
\end{array}$ & $\begin{array}{c}104114,1589 \\
1608,52397 \\
\end{array}$ \\
\hline F-Fisher & $F$ & $S_{i}^{2} / S_{a o}^{2}$ & 64,72651998 \\
\hline $95 \%$ probability & F-kritik & $F_{\text {hes }}>F_{\text {krit }}$ & 3,62 \\
\hline F-importance & $F_{\partial h}$ & $\begin{array}{l}\text { if: } F_{\text {əh }}>0.05 \\
\text { the model is } \\
\text { adequate } \\
\text { if: } F_{\text {əh }}<0.05 \\
\text { the model is not } \\
\text { adequate }\end{array}$ & $0,015214559<0,05$ \\
\hline $\begin{array}{c}\text { Student } \\
\text { coefficient-t }\end{array}$ & $\begin{array}{c}t_{R M_{1}} \\
t_{\mathrm{I} S_{1}} \\
t_{\partial M_{1}} \\
\end{array}$ & $t_{\text {hes }}>t_{\text {krit }}$ & $\begin{array}{c}-0,673101028 \\
1,10114175 \\
4,961826027 \\
\end{array}$ \\
\hline $95 \%$ probability & $t_{\text {krit }}$ & & 2,57 \\
\hline P-importance & $\begin{array}{l}P_{R M_{1}} \\
\\
\\
P_{\mathrm{I} S_{1}} \\
R_{\partial M_{1}} \\
\end{array}$ & $\begin{array}{c}\text { if: } \mathrm{P}<0.05 \\
\text { With a } 95 \% \\
\text { probability, the } \\
\text { model coefficient is } \\
\text { significant }\end{array}$ & $\begin{array}{c}0,570188209 \\
\\
0,385643055 \\
0,03829956 \\
\text { (significant) }\end{array}$ \\
\hline Standard error & $\begin{array}{l}R M_{1} \\
\dot{\mathrm{I}} S_{1} \\
\partial M_{1}\end{array}$ & & $\begin{array}{l}492,4420644 \\
12,67281485 \\
4,882202085 \\
\end{array}$ \\
\hline $\begin{array}{c}95 \% \text { probability } \\
\text { reliability } \\
\text { coefficients }\end{array}$ & $\begin{array}{l}R M_{1} \\
\dot{\mathrm{I}} S_{1} \\
\partial M_{1}\end{array}$ & & $\begin{array}{c}-2452,807023 \leq R M_{1} \leq 1789,109414 \\
-40,57215558 \leq \dot{\mathrm{I}} S_{1} \leq 68,4812691 \\
3,218217245 \leq \partial M_{1} \leq 45,2310575\end{array}$ \\
\hline
\end{tabular}


If the $\mathrm{P}$-significance values also meet the condition $\mathrm{P}<0.05$, i.e. with $95 \%$ probability, this coefficient of the model is considered significant. In the model (2) purchased for the product sold in BSR OJSC, only $R_{\partial M_{1}}$ pays for this condition, i.e. $0.03830<0.05$ condition is paid and this factor is important. The table shows that with a probability of $95 \%$, the reliability coefficients $R M_{1}\left(\dot{I} S_{1}, \partial M_{1}\right)$ are paid for all factors, i.e.

$$
\min \leq R M_{1}\left(\dot{\mathrm{I}} S_{1}, \partial M_{1}\right) \leq \max
$$

It should be noted that such models were also purchased for Neftgazmash OJSC and BOME, OJSC. The regression model obtained for Neftgazmash OJSC sold product $\left(R M_{2}\right)$ is as follows.

$$
R M_{2}=-3102,952567+23,18966263 \mathrm{I}_{2}+133,5048875 \mathrm{DM}_{2}
$$

The criteria and indicators that characterize the model are as follows.

The total correlation coefficient is $\mathrm{R}=0.999944$. The standard error is 39.12708061 . The reported value of the F-Fisher coefficient, which characterizes the adequacy of the model, is several times higher than its critical (table) value with a probability of $95 \%$, i.e. the condition $F_{\text {hes }}>F_{\text {krit }}$ is satisfied, $(756,40>3,62)$. The value of the F-importance indicator does not satisfy the condition $\mathrm{F}_{\mathrm{\partial h}}>$ 0.05 . Reporting values of $t$-Student coefficients, which characterize the individual coefficients of the model, must satisfy the condition $t_{\text {hes }}>t_{\text {krit. }}$. However, in our model $t_{R M_{2}}<t_{k r i t}(-13,8903<2,57)$, $t_{\mathrm{IS}_{2}}>t_{\text {krit }}(14,5934>2,57), t_{\partial M_{2}}>t_{\text {krit }}(34,8127>2,57)$ terms are paid. In the P-importance index, the condition $\mathrm{P}<0.05$ is satisfied for all coefficients, ie $0.0051<0.05$ for $P_{R M_{2}} ; 0.0047<0.05$ for $P_{\mathrm{I} S_{2}}$; for $P_{\partial M_{2}}$ is $0.00082<0.05$. If we look at the reliability coefficients with a probability of $95 \%$, we see that for all indicators, ie $R M_{2}\left(\dot{\mathrm{I}} S_{2}, \partial M_{2}\right)$

$\min \leq R M_{2}\left(\dot{\mathrm{I} S}{ }_{2}, \partial M_{2}\right) \leq \max$ condition is satisfied.

The relationship between the product sold for Baku Oil Mining Equipment OJSC $R M_{3}$, the number of employees $\dot{I} S_{3}$ and labor productivity $\partial M_{3}$ is characterized by the following regression equation.

$$
R M_{3}=-1014,061158+21,78525457 \dot{I} S_{2}+49,0145782 \partial M_{3}
$$

To give an economic interpretation of the obtained statistical model, let's look at its criteria and indicators. The total correlation coefficient of the model is $\mathrm{R}=0.99492$. The F-Fisher coefficient is used to characterize the model obtained for the realized product, where in any case (for example, 95\%) the reported value of this ratio must be greater than its critical (table) value, i.e. $F_{\text {hes }}>F_{k r i t}$. It is known that the critical value of the F-Fisher coefficient with a probability of $95 \% \mathrm{~F}_{\mathrm{krit}}=3.62$, and the reported value of this coefficient is

$\mathrm{F}_{\text {hes }}=97.75916006$, i.e. the condition $F_{\text {hes }}>F_{k r i t}$ is satisfied.

As for the statistical evaluation of the individual factors of the obtained model, they are performed by the t-Student criterion. Thus, a critical table value of this coefficient with a probability of $95 \% \mathrm{t}_{\text {krit }}=2.57$. The results show that this condition is satisfied for both $\mathrm{I} S_{3}$ and fəM $M_{3}$ factors, i.e. $t_{\mathrm{I} S_{3 h e s}}=3,760937715, t_{\partial M_{3 h e s}}=6,181754041$. Then the condition $t_{\text {hes }}>t_{\text {krit }}$ is satisfied for both factors, which indicates the importance of the factors included in the model.

The condition $\mathrm{P}<0.05$ must be satisfied for the individual factors in the P-importance index that characterizes the model. However, this condition is not satisfied for factor $\dot{\mathrm{I}} S_{3}$, so $P_{\mathrm{I} S_{3}}=$ 0,063987193. Hence, $P_{\mathrm{I} S_{3}}=0,063987193>0,05$, which is unacceptable. For $P_{R M_{3}}$ and $P_{\partial M_{3}}$ the condition $\mathrm{P}<0,05$ is satisfied.

If we look at the reliability coefficients with a probability of $95 \%$, for all factors, i.e. $R M_{3}\left(\dot{\mathrm{I}} S_{3}, \partial M_{3}\right)$

$\min \leq R M_{3}\left(\dot{\mathrm{I} S} \mathrm{~S}_{3} \partial M_{3}\right) \leq \max$ condition is satisfied.

The results. Summarizing all this, we note that the monitoring of the financial sustainability of these companies is important for the adaptation of production and economic activities in the OJSC under study to the laws of the market. The assessment of financial sustainability depends on the volume of products sold directly in the enterprise. The article provides two-factor regression models of the realized product for all three OJSCs and provides their mathematical-statistical analysis. The use of these models in the practical life of the OJSC is important for making operational decisions. 


\section{REFERENCES}

1. Ahmadov A.N, Mukhtarov A.N, Najafov A.S Quality assurance of oil equipment.//Azerbaijan Oil Industry, Baku: 2005, №11, p56-59

2. Mammadov K.A, Shikhiyeva L.A Estimation of service life of underground equipment in oil wells // Azerbaijan Oil Economy, Baku: 2008, №2, p45-47

3. Safarov G.A, Eyvazzade Y.T Production management and efficiency of maintenance in oil production. Baku: Çoşığlu, 2011, -208p

4. Shahbazov E.G, Mammadov E.A, Allahverdiyev K.I Ensuring the quality, reliability and safety of oil and gas mining equipment Baku: AzNQSDELI, 2007, -321p

5. Urazayeva M.D Factors affecting the production potential of the enterprises of the oil engineering industry of Azerbaijan and their assessment // Baku Business University, “Audit” magazine, 2014, №4, S101-106

6. Baranovsky M.I, Volkov Y.S, Ovseenko G.I Economic and mathematical modeling in the oil industry. // Moscow: "Nedra" 1979, 135s

7. Kovalev V.V, Volkov O.N Analysis of economic activity. Moscow: Prospect, 2000, -205s

8. Mamedov O.L Specific tasks of the DAO "Sabunchu NPO" for high-quality production of oil and gas equipment // Azerbaijan Oil Industry, Baku: 2003, No. 12, p47-49

9. Musaev A.F Oil production and oil engineering: analysis of interaction Baku, publishing house: "University of Azerbaijan", 1997, -217s

10. Revutsny A.D. Potential and value of the enterprise Moscow: publishing house "Perspektiva", 1997, -286s 